northern observatories, was incorrect and unjust, in that it overlooked the case of Dr. C. P. Olivier, for several years an astronomer in the MoCormick Observatory. I regret exceedingly this oversight, and I am at a loss to explain it, especially as Dr. Olivier was for a year a member of the staff of the Lick Observatory, and his valued astronomical contributions are thoroughly familiar to me. It is my duty and pleasure to say that the observatory of the University of Virginia, thanks in good measure to the abilities and enthusiasms of Director Mitchell and astronomer Olivier, is as efficient in good works as any existing observatory. It is greatly to be regretted that their financial resources are so limited.

I should like to say that my comments upon the astronomical situation in the southeastern states were primarily not intended to be taken in the negative sense. There was with me the hope that a public expression on the subject might lead to a better realization of existing needs, and to more adequate financial provision in the positive sense.

\section{W. W. Campbell}

\section{TECHNICAL STUDY AT OBERLIN COLLEGE}

In ScIence for December $31 \mathrm{I}$ find a note:

It is planned to establish a technical school at Oberlin College with accommodation for about seven hundred students.

This statement is not quite correct. President King has several times proposed, upon his own responsibility and doubtless merely for informal consideration, a plan for technical departments chiefly in chemical engineering and metallurgy. I believe the proposal has not yet come to the faculty for formal consideration, so of course does not have their endorsement. As all matters of internal policy and administration in Oberlin are controlled by the faculty, in accordance with an old vote of the trustees twice recently reaffirmed and now in part of the nature of a contract, it is evident the proposal has not yet taken the first formal step toward adoption. President King, who is one of the staunchest supporters of this Oberlin system, apparently thinks that it is not yet time for formal consideration of the plan. It has been mooted for two years, and indeed over fifteen years ago something of the sort was suggested, but it has received only individual consideration by members of the faculty. Judging from numerous conversations, I think the faculty, if they are asked to consider it, will decide the plan to be unwise. A general feeling among the faculty is that Oberlin's effort should be centered upon strengthening herself in every way as a college before entering upon university or technical school work.

\section{Maynard M. Metcalf}

\section{URTHER REMARKS ON “THE USE OF THE TERM FOSSIL"}

The short article entitled "The Use of the Term Fossil" published in No. 1330 of ScIENCE seems to have fulfilled the writer's object of stimulating discussion. The first criticism, by Garret P. Serviss, appeared in the Sunday American ${ }^{1}$ and while approving "poetic license" the author continues the plea for a more careful use of scientific terms by the scientist, as follows:

Half the fogs that trouble the ordinary reader when he undertakes to traverse the fields of science are due to the capricious use of words which ought to have an invariable signification.

In No. 1348 of ScIENCE, under the title "Professor Field's Use of the Term Fossil," Professor Authur M. Miller suggests the following definition: "Any trace of an organism that lived in a past Geological Age." He then states that such expressions as "fossil suncracks" and "fossil flood plains" are "illuminating" and "apt" and "are valued contributions to geological phraseology." In a recent contribution by a well-known paleobotanist, we find the term "fossil climate." Would it be considered "illuminating" or "apt" to define paleoclimatology as the study of "fossil climates"? There is a science of words as well as of things, and is it not true that much of the

1 July 22, 1920. 
misunderstanding in biological discussions arises from the misuse of such terms as $m u$ tation and saltation? We would not quibble with Archbishop Trench's remark that words simply will not stay tied as regards their meaning but are "constantly drifting from their moorings," but the more the scientist allows his vocabulary to drift the more is he disturbed by the redefined or original terms of his colleagues who, believeing it impossible to use words of two, three or more meanings, continue to inflict long-suffering humanity with an ever-increasing nomenclature. Rather do we agree with Alice who, after listening to a dissertation by Humpty Dumpty in which he makes his words mean what he chooses them to mean-" "neither more nor less," comes to the conclusion that his remarks are not particularly illuminating. Of course Humpty Dumpty was, among other things, a poet, not a geologist!

But Professor Miller also states that

The definition proposed by ... Field ... is faulty in that it errs in the time concept. He has committed the popular error of considering historic synonymous with the present geological epoch.

This is an unfortunate misstatement by Professor Miller and it is only necessary to quote from the original text to show that Field was not making the "popular error" implied.

A fossil is an object which indicates former existence of an organism which has been buried and preserved previous to historic time. According to this definition the mastodon preserved in the arctie ice is a fiossil; the leaf buried in the gutter is not.

It is also worth noting that Schuchert and others distinguish the recent or historic period as beginning the Psychozoic era. If in agreeing with this concept an error has been committed, it is certainly not a "popular" one.

Paleontology, the study of ancient life, is literally the study of fossils. Paleo is accepted in earth science as meaning geologically ancient. As a last analysis, which is the more "apt," paleo climates or "fossil climates"?
Professor Miller's constructive criticism consists of the new definition already quoted. It has the advantage of being brief, but in using the expression "past geological age" (subdivision of the present geological epoch, i.e., Bronze Age) he appears to make a very slight geological time distinction indeed. After careful reading of the whole text, we are under the impression that he means "past geological epoch" or pre-historic!

\section{Departanent of Gelogy, BROWN UNIVERSITY}

\section{THE BIOGRAPHICAL DIRECTORY OF AMERICAN MEN OF SCIENCE}

THE third edition of the Biographical Directory is now in type; it will be published as soon as the printers can complete their part of the work. The editor ventures to ask for the return of all proofs and also for information in case proof has not been received. A second copy of the proof (by letter post and with return letter postage) has been sent to those who did not return the first copy within a reasonable time. If it is not known that a scientific man can be reached at the address given, or even that he is living, it will in most cases be undesirable to include the biographical sketch.

It is gratifying that the number of those engaged in scientific work in America has increased from about 4,000 in 1905 to about 10,000 at the present time. This circumstance, however, has greatly enhanced the labor and the cost involved in the preparation of the work, and it is not possible to write individual letters of enquiry in all cases where this might be desirable. The editor consequently makes public this request for the return of the corrected proofs of all biographical sketches.

J. MoKenen Catteli

GarRison-on-Hudson, N. Y.

\section{QUOTATIONS}

WHEN AN INVENTION IS NOT AN INVENTION

There exists in our patent and copyright laws a gap which has always seemed to us a 